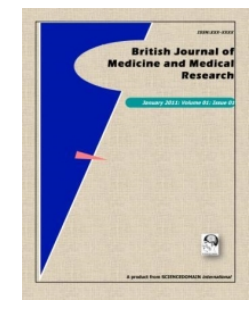

British Journal of Medicine \& Medical Research

3(3): 503-507, 2013

SCIENCEDOMAIN international

www.sciencedomain.org

\title{
Temporomandibular Joint Dislocation after Gastroendoscopy: A Case Report
}

\author{
Alper Gorkem Solakoglu ${ }^{1}$, Fevzi Yilmaz ${ }^{1^{*}}$, Engin Deniz Arslan ${ }^{1}$, \\ Miray Ozlem ${ }^{1}$, Muhittin Serkan Yilmaz $^{1}$ and Cemil Kavalci ${ }^{1}$ \\ ${ }^{1}$ Emergency Department, Numune Training and Research Hospital, Ankara, Turkey.
}

Authors' contributions

This work was carried out in collaboration between all authors. Authors AGS and FY designed the study, Author EDA wrote the first draft of the manuscript. Authors MO and MSY managed the literature searches and Author CK made final reduction. All authors read and approved the final manuscript.

Case Study

Received $16^{\text {th }}$ November 2012

Accepted $4^{\text {th }}$ February 2013

Published $27^{\text {th }}$ February 2013

\section{ABSTRACT}

Temporomandibular joint (TMJ) dislocation is defined as excessive forward movement of the mandibular condyle beyond the articular eminence with complete separation of the articular surfaces and fixation in that position. A 54 years old man attended our Emergency Department (ED) with complaints of slurred speech and inability to close his mouth after upper gastroendoscopic procedures. Lateral craniography was obtained and illustrated bilateral anterior dislocation of the patient's mandibular condyles. To confirm the diagnosis urgent radiographic imaging is required without delay as the risk of complications occurring increases as time elapses.

Keywords: Temporomandibular joint dislocation; emergency; reduction.

\section{INTRODUCTION}

Temporomandibular joint (TMJ) dislocation is defined as excessive forward movement of the mandibular condyle beyond the articular eminence with complete separation of the articular surfaces and fixation in that position [1]. Anterior dislocation has been reported to occur after opening the mouth wide such as when laughing, yawning, vomiting, taking a large bite, 
secondary to a convulsion, trauma, and iatrogenically after dental procedures and anesthesia [2]. We present a case of a male patient with bilateral anterior TMJ dislocation after upper gastrointestinal endoscopy.

\section{CASE REPORT}

A 54 years old male patient attended our Emergency Department (ED) with complaints of slurred speech and inability to close his mouth. These complaints emerged after upper gastroendoscopy that had been performed three hours earlier under local anesthesia using xylocaine and without sedation. Significant drooling, tumescence in front of the TMJ region and depression in the pre-auricular area associated with severe tenderness bilaterally were noted (Fig. 1).

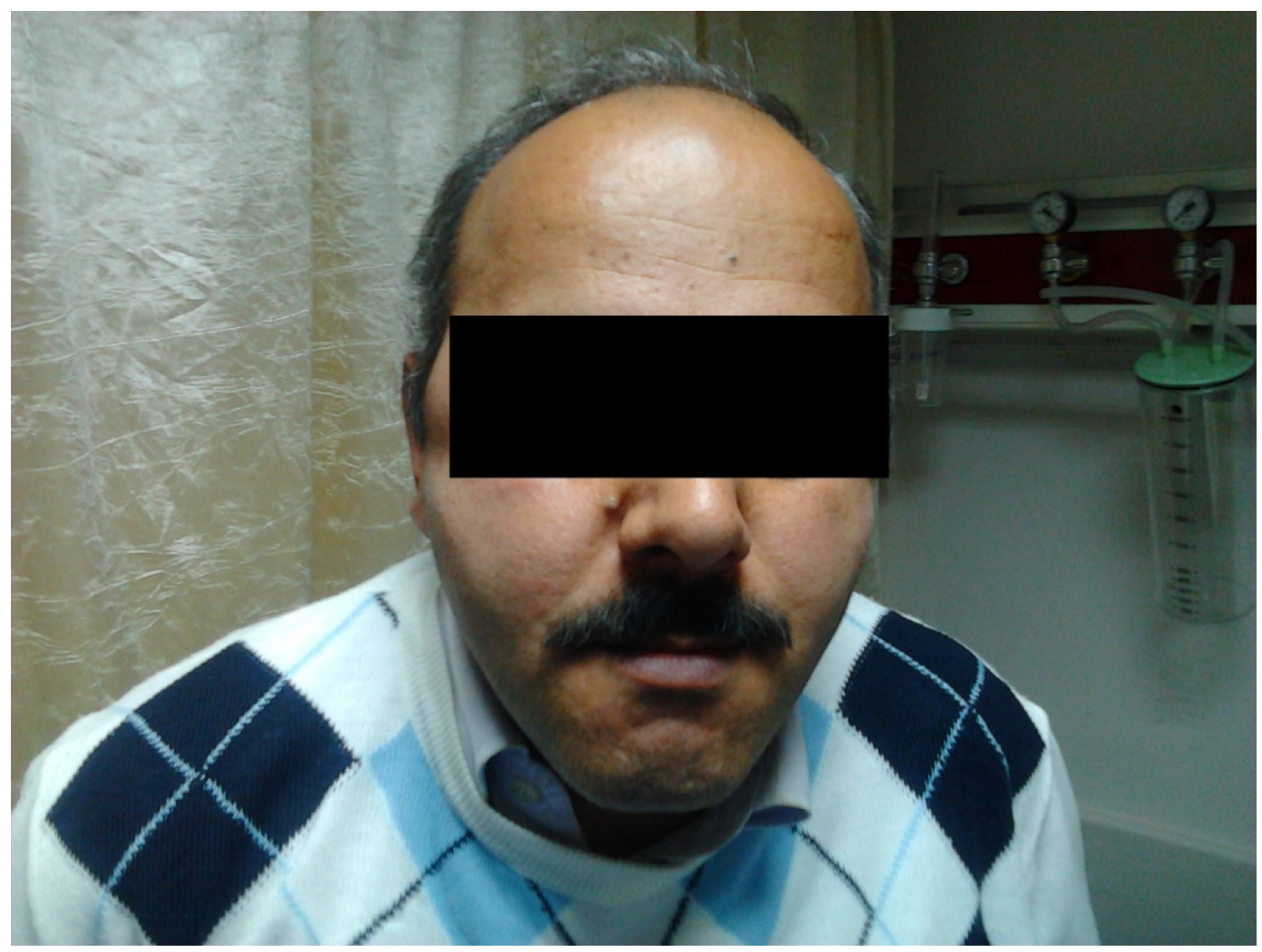

Fig. 1. A photograph showing bilateral tumescence at TMJ region

Lateral craniography was obtained that showed bilateral anterior dislocation of the mandibular condyles (Fig. 2). 


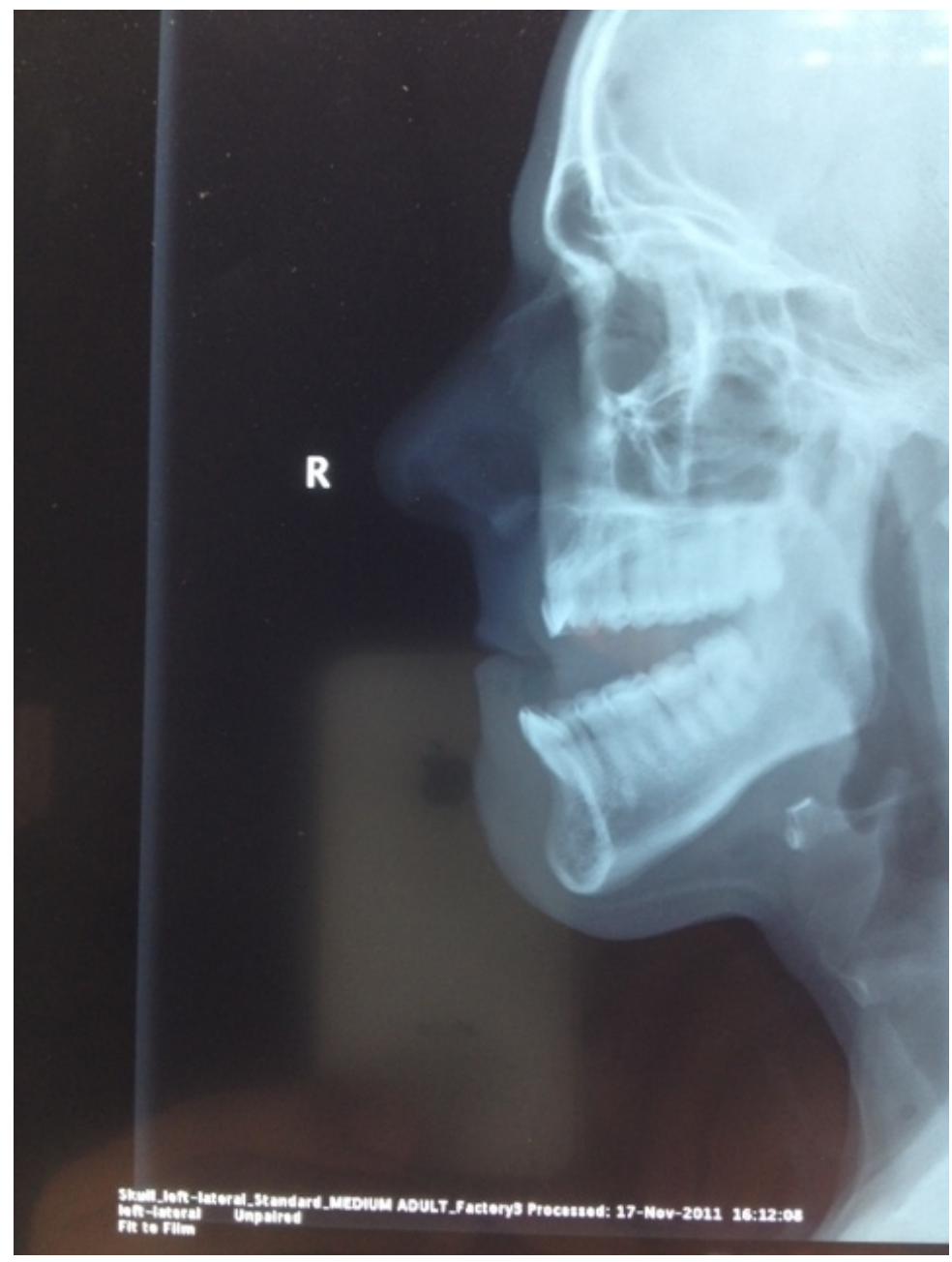

Fig. 2. Lateral craniography of the patient showing anterior dislocation of the mandibular condyles

Anterior TMJ dislocation was diagnosed and closed reduction was achieved under sedation with midazolam with Nelatons manoeuver by placing two thumbs on the patient's lower molar teeth with the fingers wrapped externally around the mandibles bilaterally and applying steady and firm pressure directed downwards and backwards [3]. He was then discharged safely after a recovery period.

\section{DISCUSSION}

TMJ dislocation rarely complicates upper gastrointestinal endoscopy. Upon reviewing the literature, five cases of anterior bilateral TMJ dislocations after upper endoscopy [4-6], two cases after transoesophageal echocardiography $[7,8]$ and one case after percutaneous endoscopic gastrostomy (PEG) tube insertion where oropharyngeal intubation was performed [9] were reported. Age, sex, endoscopist's sedation procedure varied widely and 
no risk factors can be defined. Anterior TMJ dislocation usually complicates oropharyngeal intubation.

TMJ dislocation is diagnosed clinically. Patients mostly present with TMJ pain, inability to close the mouth, pre-auricular depression, and a prominent anterior mandibular head. The presence of these clinical features requires immediate radiographic imaging so to confirm the diagnosis. If reduction is delayed subsequent spasm of masseter and pterygoid muscles make reduction more difficult [10]. Closed reduction should be attempted. Here, the usual technique for reduction of dislocated TMJ was used. However there are some other methods that have been reported in the literature for reduction of TMJ dislocation including the extraoral technique [11], combining the extraoral and intraoral route [12] and the gag reflex procedure [13].

If closed reduction fails open reduction should be performed [14]. After reduction the patient must be informed about appropriate diet and mouth opening. Anti-inflammatory drugs can be used for pain relief.

\section{CONCLUSION}

TMJ dislocation is a real emergency, easily managed and completely treatable. To avoid TMJ dislocation care should be taken not to open the mouth beyond the physiological limit during gastroendoscopy or oropharyngeal intubation. The recognition of the diagnostic criteria of TMJ dislocation that may complicate these procedures is important to minimize the risk of missed or delay in diagnosis of dislocation. Further investigation is needed to define risk factors after upper endoscopic and oropharyngeal manipulation.

\section{CONSENT}

All authors declare that 'written informed consent was obtained from the patient for publication of this case report and accompanying images.

\section{ETHICAL APPROVAL}

All authors hereby declare that this manuscript have been performed in accordance with the ethical standards laid down in the 1964 Declaration of Helsinki.

\section{ACKNOWLEDGEMENT}

Special thanks to Doruk Uludag for his contribution.

\section{COMPETING INTERESTS}

Authors have declared that no competing interests exist.

\section{REFERENCES}

1. Vasconcelos BC, Porto GG, Lima FT. Treatment of chronic mandibular dislocations using miniplates: follow-up of 8 cases and literature review. Int J Oral Maxillofac Surg. 2009;38(9):933-6. 
2. Haddon R, Peacock IV WF. Face and jaw emergencies. In: Tintinalli JE, Kelen GD, Stapczynski JS. editors. emergency medicine: A Comprehensive Study Guide. $6^{\text {th }}$ ed., New York: McGraw-Hill; 2004.

3. EL Bouazzaoui A, Labib S, Derkaoui A, Adnane Berdai M, Bendadi A, Harandou M. Dislocation of temporo-mandibular joint - an uncommon circumstance of occurrence: vaginal delivery Pan Afr Med J. 2010;5:2.

4. Lacy PD, Lee JM, O'Morain CA. Temporomandibular joint dislocation: an unusual complication of upper gastrointestinal endoscopy. Am J Gastroenterol. 2000;95(12):3653-4.

5. Mangi Q, Ridgway PF, Ibrahim Z, Evoy D. Dislocation of the mandible. Surg Endosc. 2004;18(3):554-6.

6. Nijhawan S, Nepalia S. Dislocation of temporomandibular joint after upper gastrointestinal endoscopy. Trop Gastroenterol. 1994;15(4):232.

7. Anantharam B, Chahal N, Stephens N, Senior R. Temporo-mandibular joint dislocation: an unusual complication of transoesophageal echocardiography. Eur $\mathrm{J}$ Echocardiogr. 2010;11(2):190-1.

8. Roche NC, Paule P, Fourcade L. Temporomandibular joint dislocation during transoesophageal echocardiography: an unusual complication. Arch Cardiovasc Dis. 2011;104(8-9):482-3.

9. Rosemore J, Nikoomanesh P, Lacy BE. Bilateral temporomandibular joint dislocation after PEG tube placement. Gastrointest Endosc. 2004;59(1):146-7.

10. Nusrath MA, Adams JR, Farr DR, Bryant DG. TMJ dislocation. Br Dent J. 2008;204(4):170-1.

11. Chen YC, Chen CT, Lin $\mathrm{CH}$, Chen YR. A safe and effective way for reduction of temporomandibular joint dislocation. Ann Plast Surg. 2007;58(1):105-8.

12. Shun TA, Wai WT, Chiu LC. A case series of closed reduction for acute temporomandibular joint dislocation by a new approach. Eur $\mathrm{J}$ Emerg Med. 2006;13(2):72-5.

13. Awang MN. A new approach to the reduction of acute dislocation of the temporomandibular joint: a report of three cases. $\mathrm{Br} \mathrm{J}$ Oral Maxillofac Surg. 1987;25(3):244-9.

14. Young AL, Thomas DC, Quek SY. Use of masseteric and deep temporal nerve blocks for reduction of mandibular dislocation. Anesth Prog. 2009;56(1):9-13.

(C) 2013 Solakoglu et al.; This is an Open Access article distributed under the terms of the Creative Commons Attribution License (http://creativecommons.org/licenses/by/3.0), which permits unrestricted use, distribution, and reproduction in any medium, provided the original work is properly cited.

Peer-review history:

The peer review history for this paper can be accessed here: http://www.sciencedomain.org/review-history.php?iid=194\&id=12\&aid=983 